\title{
Highlighting Cultural Confidence: Subject for the Construction of Campus Culture in Institutions of Higher Learning in the New Era
}

\author{
Li Jiang, Ke Xiaohua ${ }^{a}$ ** \\ Guangdong University of Foreign Studies, Guangzhou, Guangdong, China \\ a896503618@qq.com \\ *corresponding author
}

Keywords: campus culture, new era, cultural confidence, institutions of higher learning, construction.

\begin{abstract}
Currently, socialism with Chinese characteristics has crossed the threshold into a new era. Highlighting cultural confidence is the goal and requirement for the construction of campus culture in Chinese institutions of higher learning in the new era. In the construction, it is necessary to adhere to the orientation of advanced socialist culture, the inheritance and innovation of fine traditional Chinese culture, international philosophy, and the principle of fostering virtue through education and focus on the project on the inheritance and innovation of fine Chinese culture so as to establish cultural confidence; attach importance to the education of fine traditional Chinese culture and cross-cultural education so as to cultivate cultural confidence; create a multicultural atmosphere so as to improve cultural confidence; and build cross-cultural experience platforms so as to enhance cultural confidence, and make more efforts to promote the construction of campus culture in institutions of higher learning in the new era.
\end{abstract}

\section{Introduction}

According to General Secretary Xi Jinping's report at 19th CPC National Congress, "With decades of hard work, socialism with Chinese characteristics has crossed the threshold into a new era." Also, the significance of cultural construction has risen to unprecedented heights, "Culture is a country and nation's soul. Our country will thrive only if our culture thrives, and our nation will be strong only if our culture is strong. Without full confidence in our culture, without a rich and prosperous culture, the Chinese nation will not be able to rejuvenate itself." As an important part of social culture, campus culture in institutions of higher learning shoulders important missions in the cause of training qualified builders and reliable successors for socialism with Chinese characteristics in the new era, and also plays an important role in the tasks of socialist construction including inheriting and developing fine Chinese culture and prospering and developing advanced socialist culture. Against this background, institutions of higher learning are facing the huge issue of moving with the times and strengthen the construction of campus culture that highlights cultural confidence.

\section{Current Situation and Trend of China Domestic and Overseas Research}

According to existing literature, there are rich papers and monographs on the study of construction of campus culture. Chinese scholars began the study on it in1986, and it has gradually become a research hotspot in the field of ideological and political education in institutions of higher learning. China Domestic research mainly focuses on the definition, characteristics, functions, significance, development stages, mechanism and mechanism construction, and construction methods of campus culture. Despite few research results on international construction of campus culture in institutions of higher learning, Chinese scholars has started to discuss their understanding of the connotation and essence of "international perspective", and explored the problems and challenges for campus culture in institutions of higher learning under the international background. 
More mature in theories and practice than domestic research, foreign research not only attaches importance to the construction of material culture, but also puts more emphasis on people-centered philosophy, demonstration of personality, importance of individuals, practicability and freedom, and international exchange and cooperation. Both China domestic and foreign scholars have studied the construction of campus culture from multiple perspectives and directions. However, there is still no research on the construction of campus culture in institutions of higher learning in the new era. In China, new era is a special noun phrase indicating that socialism with Chinese characteristics has developed into a new stage, and thus institutions of higher learning are facing new objectives and tasks in the new era. By keeping pace with the times and leveraging literature method, logical analysis, materialistic dialectics to explore requirements, principles and realization methods for construction of campus culture in institutions of higher learning in the new era, it is our hope for this project to enrich the content of theoretical research on construction of campus culture, expand the research field of construction of campus culture, and to some extent supplement research on construction of campus culture in institutions of higher learning in the new era.

\section{Highlighting Cultural Confidence is the Requirement for the Construction of Campus Culture in Institutions of Higher Learning in the New Era}

(1) Cultural confidence needs to be highlighted in the complex and volatile international situation. With the development of economic globalization and social informatization, cultural and educational exchanges between different countries and regions have also been increasingly frequent. Under Trump presidency, America is intensifying its efforts to disturb and hit China, and pursuing "America first" unilateralism and protectionism. Moreover, America has launched a trade war and ridden a wave of anti-globalization. However, governments of the world are opposing those efforts. Particularly, China has always firmly upheld and advocated inclusive and open development of global economy, proposed and actively advanced "the Belt and Road" Initiative, and worked with other countries, at the height of building a community with shared future for humanity, to promote strong, sustainable, balanced and inclusive growth of world economy. As a "stabilizer" for world economy, a defender of economic globalization, a participator, constructor and leader in promoting world peace and development, China has won endorsements and support from most countries, established the image of a responsible great power, and taken center stage in the world with more and more confidence. The confidence stems from the overall improvement of China's comprehensive national strength and influence, which has enabled China to provide Chinese wisdom and approach for human problems and also Chinese people's national identity and confidence in the path, theory, system, and culture of socialism with Chinese characteristics. Cultural confidence is more fundamental, in-depth, and enduring power. Through the increase of cultural confidence among among the whole Chinese nation, China's national cultural soft power and core competitiveness can be improved, and strong spiritual power can be provided for upholding and developing socialism with Chinese characteristics, and for realizing the Chinese Dream of the great rejuvenation of the Chinese nation.

(2) Cultural confidence needs to be highlighted in the changing domestic social circumstances. As socialism with Chinese characteristics has crossed the threshold into a new era, it has been pointed out in the report of 19th CPC National Congress that "Previously the principal contradiction was described as one between "the ever-growing material and cultural needs of the people and backward social production", and "What we now face is the contradiction between unbalanced and inadequate development and the people's ever-growing needs for a better life." It means that modern-day Chinese people's needs have changed profoundly from mainly meeting the material needs into mainly satisfying the spiritual needs. Meanwhile, the satisfaction of the people's cultural needs is an important part of meeting the people's ever-growing needs for a better life. Institutions of higher learning have the responsibilities to lead social culture as well as to cultivate students. As one of the main drivers for promoting and leading the development of mainstream culture, they are important places for cultural construction; sources, pioneers and exchange centers for new thoughts; communicators for fine culture; and pools of cultural thoughts for the society ${ }^{[1]}$. As an important 
way for university students to carry out social activities, cultural activities in the campus are directly related to their spiritual and cultural needs. With the changes of the times as well as economic and social development, new requirements and changes have emerged in the spiritual and cultural life of university students. Their psychological development, aesthetic orientation, moral judgment, value orientation, political ideals, and other spiritual and cultural needs are contradictory, particular and changeable. Therefore, there is an urgent need for campus culture that conforms to social mainstream ideologies and promotes socialist core values, so that students can be infused with this culture, their quality can be improved, and they can be well cultivated. In this way, institutions of higher learning will be able to become leading areas that drive social culture, and develop people of the times who have high cultural confidence, Chinese soul, global competence, and the ability to undertake the mission of national rejuvenation.

(3) Cultural confidence needs to be highlighted in the development of institutions of higher learning. As an important indicator for the international competitiveness and society contribution of universities, international talent cultivation has been a remarkable feature of world-class universities $^{[2]}$. China started to "promote the construction of world-class universities and first-class disciplines " in August 2015 based on the basic approach and strategic option for the development of higher education under China's national conditions. It has been specified that China must build world-class universities with Chinese characteristics to promote the development of higher education and enhance China's core competitiveness. As the material and spiritual culture formed and developed by schools, campus culture embodies the cohesiveness and creativity of culture, and plays an important role in nurturing the independent personality and spirit of teachers and students, and in improving the comprehensive quality of students. It is one of the most important core competitiveness of modern universities, and the source of power for the sustainable development of universities. It largely determines the orientation, overall features, social image and development trend of universities. Therefore, it is an indispensable link for all institutions of higher learning in the construction of world-class universities. In the process of construction, we can not copy the modes of other universities indiscriminately while benchmarking world-class universities, or we can never catch up with them. We should highlight Chinese characteristics and focus on the construction of "world-class universities" with Chinese characteristics in order to overtake them. When exploring and learning from advanced cultural ideas and construction modes, we need to hold fast to the cultural traditions of Chinese nation and universities, and establish high confidence in advanced socialist culture and fine traditional Chinese culture, so that our culture will not be destroyed or homogenized by foreign cultures in the process of cultural exchange, interaction and integration.

\section{Principles for Highlighting Cultural Confidence in the Construction of Campus Culture in Institutions of Higher Learning in the New Era}

(1) Adhering to the orientation of advanced socialist culture and underscoring the system of core socialist values are the spirits in the construction of campus culture in institutions of higher learning in the new era. Campus culture in institutions of higher learning is a mirror of the historical development, cultural deposits, humanism, and other aspects of schools; common values, ideas and pursuits recognized by institutions of higher learning; and a significant component of the construction of advanced socialist culture ${ }^{[3]}$. In China, it is determined by the nature of socialist institutions of higher learning to train builders and successors for the cause of socialism with Chinese characteristics with adherence to the socialist orientation for running a school. Currently, teachers and students in institutions of higher learning are constantly impacted by diverse and intricate social thought, as well as coexisting advanced, backward, healthy and decadent cultures. To improve social ideological consensus and reinforce the cohesiveness of teachers and students to form positive and healthy campus culture, we must improve cultural confidence; insist on the correct development direction for the construction of campus culture; never waver in our commitment to core socialist values; leverage the scientific worldview and methodologies provided by materialistic dialectics and historical materialism to conduct logic analysis, guide through theory; establish and measure the standards for the values of advanced culture; and eliminate the false, 
retain the true, and extract the essentials. As the soul of Chinese rejuvenation and the essence of advanced socialist culture, the system of core socialist values determines the development direction of socialism with Chinese characteristics. In order to adhere to the orientation of advanced socialist culture, we must establish the system of core socialist values; cultivate and pursue socialist core values in the construction of campus culture in institutions of higher learning; enhance our initiative and say in the field of ideologies; and thus guide social thought and provide spiritual guidance for the construction of campus culture.

(2) Adhering to the inheritance and innovation of the fine traditional Chinese culture is the basis for highlighting cultural confidence in the construction of campus culture in institutions of higher learning in the new era. In the thirteenth collective study of the Political Bureau of the CPC Central Committee, General Secretary Xi Jinping pointed out: "Abandoning traditions and losing the foundation is tantamount to sever a nation's spiritual lifeline. The extensive and profound traditional Chinese culture is our foothold in the swift current of the world culture." The Chinese civilization is the only uninterrupted civilization among the four ancient civilizations. The fine traditional Chinese culture is time-honored and profound, which embodies the ideas and emotion, morality and virtue, social belief and pursuit of the Chinese nation formed in its long course of historical development. It has served as the nation's continuous and growing spiritual power since ancient times and the source of the core socialist values. It not only has a profound impact on the values and lifestyle of Chinese people and China's development path, but also plays a major role in promoting human progress and development. This is the basis for the cultural confidence of Chinese people. With the rise of globalization, some western countries take advantage of their strong economic strength and advanced information technology to aggressively push forward the cultural colonialism under the cover of "cultural globalization" and "cultural integration", so as to damage local cultures of other countries. Whether a country can maintain its fine national culture is not only related to the survival and development of its own culture, but also to the destiny and future of the country. Institutions of higher learning have the function of inheriting and innovating the national culture, and thus campus cultural construction is an effective carrier of cultural inheritance and innovation. With the in-depth exploration of the ideological concepts, human spirit, and code of ethics contained in the fine traditional culture of the Chinese nation and meeting the requirements of the times, it is necessary to educate teachers and students on the fine traditional Chinese culture, develop their love and sense of identity for the national culture, and boost their cultural confidence, so that they can protect and carry forward their national culture and safeguard national interests in face of cultural hegemony.

(3) Establishing the concept of internationalization and upholding an open and inclusive mindset is an insight for highlighting cultural confidence in the construction of campus culture in institutions of higher learning in the new era. After the 19th National Congress, a more open and confident China has been presented to the world. Internationalization is a trend that does not reverse. The change and development of internationalization is inevitable along with the reform and development of institutions of higher learning in the world, and it is also the result of the globalization of the world economy and politics ${ }^{[4]}$. In this context, China's institutions of higher learning should start from an international vision and carefully identify their positions in the coordinate system of global universities, so as to make rational trade-offs and reflections on the long-term development of institutions of higher learning. The campus cultural construction also faces the same challenge. Institutions of higher learning should not only stand at the forefront of the development of the times, but also correctly handle the relationship between local culture and foreign culture. Institutions of higher learning should be opposed not only to cultural nihilism, cultural revivalism, and narrow cultural conservatism, but also to Western-centrism and cultural colonialism. Institutions of higher learning should also realize that internationalization will inevitably bring about mutual collisions and impacts among various cultures, follow the principle of mutual tolerance, mutual respect and mutual learning, recognize the diversity of culture, and fully learn from the world's outstanding civilizations with a broad vision, liberal attitude and an open mind. Institutions of higher learning should draw on the advanced experience and strengths of campus cultural construction in all countries of the world, and actively find new ways of campus 
cultural construction in China, so as to make campus culture not only deeply rooted in the fertile soil of Chinese culture, but also adaptable to the trend of world development.

(4) Adhering to foster virtue through education, moralize and educate people with culture and cultivate groups of people with a sense of cultural mission is the foothold for highlighting cultural confidence in the construction of campus culture in institutions of higher learning in the new era. To strengthen the national cultural soft power and boost cultural confidence is, in the final analysis, to cultivate cultural entities from generation to generation, that is, the masses of people, especially the young students. The foundation of institutions of higher learning is moral education, so it is necessary to give full play to the moral education function of campus culture, highlight the characteristic of educating people with culture so as to serve the foundation of moral education. Campus cultural construction plays an important role in fostering and improving students' comprehensive quality. In the new era, Chinese institutions of higher learning should cultivate people who have all-round attainments in moral, intellectual, and physical development, people who have great cultural accomplishment and love their fine traditional culture, people who take an open attitude towards culture and rationally treat cultures of other nations and countries with a global vision, and people who can maintain cultural confidence and have the courage and wisdom to undertake cultural missions that history and the times have entrusted to them.

\section{The Path to Highlight Cultural Confidence in the Construction of Campus Culture in Institutions of Higher Learning in the New Era}

(1) Give priority to the project of inheriting and developing fine traditional Chinese culture and vigorously promote the campus cultural construction under the socialism with Chinese characteristics in the new era to build cultural confidence. In January 2017, the General Office of the CPC Central Committee and the General Office of the State Council issued the "Opinions on Implementing the Project of Inheriting and Developing the Fine Traditional Chinese Culture", proposing that "the fine traditional Chinese culture should be fully integrated into all links of ideological and moral education, cultural knowledge education, artistic and physical education and social practice, and play its role throughout fields of formative education, basic education, vocational education, higher education, and adult education." In May 2018, Chinese Ministry of Education issued the "Notice on the Base Construction for the Inheritance of Traditional Chinese Culture", planning to build about 100 bases for the inheritance of traditional Chinese culture across the country by 2020, and explore the establishment of inheritance and development system with campus characteristics for the fine traditional Chinese culture. These two documents provide policy guidance and support for institutions of higher learning in terms of the inheritance and development of fine traditional Chinese culture. Following the guidance of the two documents, the campus cultural construction of all institutions of higher learning should be planned at the top level from the strategic perspectives of school's overall development and talent training, with key points highlighted and progress made on the whole and pay more attention to Chinese cultural elements in such areas as building up campus spirit, organizing campus cultural activities, and creating campus cultural environment. We should insist on leading campus cultural construction with the core socialist values, take a correct view of the relationship between Chinese and Western cultures and neither worship everything foreign nor undervalue our own culture. In the process of carrying forward the fine traditional culture, we are supposed to focus on the consolidation of cultural foundation and maintenance of cultural traditions. When carrying out cultural studies and cultural activities, we need to explore Chinese stories that are rich in culture and conform to the spirit of the times, creating high-level, high-quality brand projects that carry forward the fine traditional culture, revolutionary culture, and advanced socialist culture of the Chinese nation. It is imperative to win young students' love and recognition of the fine traditional culture in the way they like to enhance their national self-esteem, national confidence and national pride, so that they can develop positive and healthy aesthetic standard and correct values while influenced by the fine Chinese culture, and can learn Chinese wisdom from our culture, and thus are willing to become the envoy of Chinese culture to carry forward the Chinese spirit and spread Chinese values. 
(2) Attach importance to the education on the fine traditional Chinese culture and cross-cultural education to foster cultural confidence. Institutions of higher learning will incorporate the courses on the fine traditional Chinese culture into the curriculum systems of public art and public physical education, add courses of cross-cultural education such as cross-cultural communication, Chinese and foreign etiquette, and comparison of Chinese and Western cultures and stipulate corresponding credits. We should encourage studies on sinology and the comparison of Chinese and Western cultures and set up relevant research institutions. A series of academic lectures on sinology should be organized according to schedule and local cultural resources should be fully tapped by inviting inheritors of local intangible cultural heritage projects, national folk art, traditional crafts and national traditional sports to lecture or perform in our universities so as to strengthen the promotion and spreading of inheritance projects and push forward campus construction of cultural innovation, further to popularize and carry forward the fine traditional culture of the Chinese nation. We should give full play of classroom teaching as the major channel for education, emphasize on educating and moralizing people with culture, introduce in time the latest outcome in theoretical innovation and the latest achievements China has made to the teaching materials and the classroom and finally to students' mind, and enhance students' confidence in the path, theories, system, and culture of socialism with Chinese characteristics. It is necessary to strengthen the education on national conditions and international situation, teach students to correctly understand the world and China's development trend, enhance college students' sense of responsibility of the times and consciousness of historical missions, and encourage them to fulfil their youthful dreams based on Chinese dream. Great efforts should be made to train and guide sinology associations and other student organizations aiming to carry forward the fine traditional Chinese culture and give them strong support in the allocation of funding, place and manpower.

(3) Create a multi-cultural environment and make campus a window of international understanding and cultural integration to boost cultural confidence. Campus culture has a subtle influence on college students' ideas, value orientations and behavior patterns, and thus plays an important role in educating people. Against the background of diverse cultures, institutions of higher learning need to have an international vision and make the internationalization of campus culture as an important part of campus cultural construction. We should take international cooperation and exchange as a breakthrough step, and take active actions to build a rich and diverse campus culture for cross-cultural communication. For example, we can conduct cultural exchange with foreign universities by offering multicultural activities such as World Cultural Festival, Europa Cultural Festival, Asian Cultural Festival, Chinese Cultural Festival, Model United Nations Conference. In this way, institutions of higher learning will become a window for domestic college students to understand the world, the world culture, and the multiculturalism and also a window for foreign students to understand China, the Chinese people, and the Chinese history and culture at the same time, so that college students can develop a cross-cultural mentality featuring equality, openness, and inclusiveness and form an objective, unbiased cross-cultural concept in such campus environment. Institutions of higher learning should make good use of the opportunities of foreign exchange. We need to actively learn the advanced values from the external culture of the school, strive to explore the common factors in the diversified values, and then strengthen the cohesiveness of the values dominated by campus culture. Through international exchange programs, institutions of higher learning provide more opportunities for exchange study or internship abroad, so that college students can improve their cross-cultural communication ability and increase cultural confidence in international exchange, integrating international mindset into regular thinking mode.

(4) Adhere to be practice-oriented and build a platform for cross-cultural experience to boost cultural confidence. The essence of culture is about spirit, emotion, and aesthetics, and therefore the best way to learn about culture is to experience it. It is more effective than the lectures to let students feel the charm of fine cultures in person. Apart from making great efforts to introduce high art into campus through inviting famous masters and art troupes from home and abroad, so that students can take a close look at them. we also need to explore and make full use of local cultural resources, including various historical and cultural sites, museums, memorials, intangible cultural 
heritage projects and so on. Through visits, practice and on-the-spot teaching, students can learn about history and culture, make a comparative study and get personal experience, which makes it easier for them to understand traditional Chinese culture, revolutionary culture, socialist culture and foreign culture and at the same time to accept education on patriotism, collectivism and socialism. Institutions of higher learning should actively explore the base construction of cross-cultural education for college students. We are supposed to organize and guide college students to participate in cultural construction activities and cultural activities for public welfare such as activities related to community culture, corporate culture, and military camp culture. Engaging in social services and joint cultural construction can help students learn more about the conditions of our nation, people and society. In this way, students get a correct understanding of our country, increase cultural confidence, and stay firm in striving for the great rejuvenation of the Chinese nation $^{[5]}$.

\section{Conclusion}

To enhance cultural confidence and strengthen national cultural soft power remains not only the theme of cultural construction of socialism with Chinese characteristics in the new era, but also the theme of campus cultural construction. Institutions of higher learning should firmly grasp the new characteristics and rules of the new era, as well as the new opportunities and challenges facing the campus cultural construction. With an international vision, it is imperative to further shape a better image of Chinese university, develop school running characteristics, enhance school running strength and core competitiveness, and constantly explore new ways and methods of campus cultural construction, so as to play an important role in inheriting and innovating culture, setting a good example and making a difference in all aspects.

\section{References}

[1] Zhang Xuri (2012). Rethink on Campus Cultural Construction-From the Perspective of Prosperous Development of Socialist Culture. Journal of Guangdong Polytechnic Normal University, 5, 48-51.

[2] Wang Genshun, Wanghui (2009). Exploration and Practice of Internationalization of Talents Training in Research-based Universities. Journal of National Academy of Education Administration, 4, 32-37.

[3] Xie Shoucheng, Xiao Wei (2011). China’s Campus Cultural Construction from the Perspective of Internationalization-Challenge and Strategy. Ideological and Political Education Research, 5, 36-39.

[4] Wu Jian (2009). The International Development of Contemporary Higher Education. Beijing: People's Publishing House, 263.

[5] Li Jiang (2012). Campus Cultural Construction under the Vision of Prosperous Development of Socialist Culture. Journal of Henan Institute of Education, 12, 20-21. 